\title{
An Analysis of Sexism in English
}

\author{
Guimei He \\ Qingdao University of Science and Technology, Qingdao 266061, China \\ Email: hkmei@163.com
}

\begin{abstract}
Language plays an important role in society. As a phenomenon of society, language reflects all the sides of human society naturally. Sexism in language has long been a heat topic in sociolinguistics. By looking at the sexism in English and relating it to the relevant linguistic theories, this paper tries to make an analysis of sexism in the use of language through comparison, induction and exemplification. The purpose is to disclose some of the features of English language that suggest cultural biases and socially unjust attitudes towards women. The study will help us to have a better understanding of the relationship between language and society.
\end{abstract}

Index Terms - sexism, English language, comparison, reason

\section{INTRODUCTION}

Language is far from merely reflecting the nature of society; it serves as a primary means of constructing and maintaining that society. Its existence and development are closely linked with the social attitudes of human beings and to a great extent are affected by their social views and values, so people's socio-cultural behaviors and attitudes as well as thoughts are reflected in their use of the language. "Sociolinguistics is the science which studies the relationship between language and society, between the use of language and the social structures in which the users of language live. It is generally recognized that sociolinguistics as an independent discipline arose in the mid 1960s". Historically and sociologically, our society is man-oriented and man-centered. Gender discrimination is felt and found universally, Women have been considered to be inferior to men. They have been discriminated in one way or another. Sexism in English is a reflection of sexism in social reality. Until now sexism still exists in language and women have a language of their own, which is different from and inferior to the language of men in the society. According to Ralph Fasold, she studied this issue about sex and language systematically, she claimed that women experience linguistic discrimination in two ways; in the way they are taught to use language and in the general way language used treats them .Further she concluded that both ways tend to degrade women to a lower position. This paper emphatically introduces and analyzes the specific phenomena of sexism. Since that sexist language helps to reinforce the sexist social structure and that English is becoming an international language, documentation of linguistic sexism in this thesis is of practical significance.

\section{Morphological FEATURE OF SEXISM IN ENGLISH}

\section{A. Derivation}

"In English, derivational morphemes are mainly prefixes and suffixes. These affixes often change the part of the stem. The affixes thereby help us to identify relationships within words". Derivation is a way of word formation. It forms a word with meaning and category distinct from that of its base through the addition of an affix. The original base is the core of the formed word and carries the main complements of its meaning. The affixes are always bound morphemes, which carries information about meaning or function.

In English lexicon, one of the most obvious evidences of the sexism is the affixes which lead to a view of women as a derivation from a male term. The feminine one is always derivative of the masculine one by adding a feminine suffix such as -ess and -ette. Actor, for instance, with the meaning of " a person who plays the part of a character in a movie or play" , when attached to a feminine suffix -ess, becomes actress with the meaning of " woman with profession similar to those of actor" . And as for -ette, when usher is adhered to -ette, it becomes usherette. Such pairs of the words are of long lists in English lexicon. Here just list some of them:

$\begin{array}{ll}\text { Masculine } & \text { Feminine } \\ \text { ambassador } & \text { ambassadress } \\ \text { duke } & \text { duchess } \\ \text { prince } & \text { princess } \\ \text { poet } & \text { poetess }\end{array}$

This kind of word-formation seems to tell that women are derived from men and attached the men, from which we can come to conclusion that the addition of a feminine suffix to masculine human agent nouns usually does more than simply change the gender reference of the word, it often attaches a meaning of triviality, of lesser status or dependence to the term. It shows that woman is affiliated to man, so it is a kind of linguistic discrimination against women. 
But with further insight into the meaning of such pairs, we may find that the suffix-ess not only marks the secondary position of the feminine words but also connotes the relationship between the female and male reference to the pair of words. Let us compare the pair of governor with governess. Governor is a ruler of a country, city and associates with power and high social status as well as honor and dignity; while governess is a woman employed to teach young children in their home. Because of the gender differentiation, these two words have dramatically different meanings, the masculine one of which belongs to high social class, but the feminine one marked with -ess belongs to a lower social class. Just like Song Hongbo's interpretation of Baron's statement that in the main cases, the usage of feminine suffixes indicates that feminine nouns are derivation of masculine nouns, which leads to the subordinate status of feminine words.

By making observation of many feminine words, which are formed through derivation by adding the suffix-ess, I made induction that -ess is far a suffix marking the female category, it has semantic meanings. Preference for but discrimination against female can be clearly seen in ways of word formation.

Another aspect concerned with this point is that English sex-paired words(here referring to the pair of words with gender contrast) the masculine one has greater flexibility in word-formation and mainly has a wider distribution of meaning. Take the pair of man- and woman- for instance (man- and woman- here are roots in the process of word formation). "Manhood" has three meanings in the Oxford Advanced Learner's Chinese-English Dictionary. (1)state of being a man, (2)qualities of a man, eg. courage, manliness,(3) a men of a country, while womanhood only has one meaning concept of" state of being woman". By comparison, it is clear that manhood has two more meaning concepts than womanhood. What means by having more meaning concepts? According to Hu Zhuangling, words are symbol of physical entities in reality. In this sense, the masculine words with much more meaning concepts reflect that men have more chance in social activities and in turn a more efficient way to express themselves and reinforce the masculine imagery. It comes to a conclusion that masculine words are common and general, while feminine words are mainly formed by attacking suffixes on the basis of the masculine words. Just like Song Hongbo's interpretation of Baron's statement that in the main cases, the usage of feminine suffixes indicates that feminine nouns are derivation of masculine nouns, which leads to the subordinate status of feminine words.

\section{B. Compound Words}

"Compound is another common way to build words in English through the combination of lexical categories" English itself has no difference of gender. There are many neutral words. Many professionals such as doctor, engineer, lawyer, professor, judge, and surgeon can be used to indicate both males and females. However, actually due to the long-stereotyped view of the relationship between gender and profession, such word conventionally refers to one gender, either male or female. For example:

(1)My cousin is an engineer. (2)My cousin is a nurse.

Nine out of ten come with the first response that "my cousin" in sentence (1) is male and in sentence (2) female. Only one of all ten tells with hesitation whether "my cousin" is female or male. Professions involving power and strength such as 'president'and'chairman'are more likely to be associated to men, because these satisfactory jobs are traditionally viewed as ones qualified only by males. But when indicating female's position, professions, etc, these words are created by adding a bound morpheme or by combining them with a word referring to female, a compound form of combination of a female title such as woman, female, lady or madam and the professional term comes into use, for example, woman lawyer and madam chairman. On the other hand, professions involving patience, service or lower social status are more likely to be associated with woman, for example, nurse, dressmaker and secretary. If on special occasions a male involved, then the compound form of a masculine title male or man and a professional term is used for example, newsman, policeman, businessman, fireman, salesman, fisherman, etc. It makes clear that men monopolize the high status professions. Women can only do service work or low social status work. Take the compound word "callboy" and "call girl" for example. The former refers to the waiter in hotel or the person who calls the player ready to stage in theatre; the latter means the prostitute summoned by phone. These words have manifested the discrimination of language towards female from the angle of word matching

Differentiation of professions in accordance with sex distinction may lie in social conventions by which sex is a standard in allocating tasks, rights and responsibilities. Thus men and women play different roles in society. Women are mainly constrained to domestic trifles and baby -rearing, while men work outside paid as the breadwinner. So prejudice becomes convention. Using compound forms to specify professions between men and women is somehow a reflection of the reality that women are exclusive from professions with higher social status and to some extent the form of language usage in turn reinforces such a social phenomenon.

\section{SYNTACTIC FEATURES OF SEXISM IN ENGLISH}

\section{A. Generic Pronouns}

In English there are a group of nouns of common gender, which refer to either male or female such as student, person, teacher, etc. When such nouns are used with generic reference in single form, the traditional grammar advocates to use the masculine pronouns in the context for the purpose of coherence with generic nouns.( Zhang Zhenbang,1995).

Generic pronouns are pronouns that are said to refer, with equal likelihood, to woman and men. But the English 
language ignores women by allowing masculine terms to be used specifically to refer to males and commonly to refer to human beings in general. The generic pronoun "he" is perhaps the most well known example of the gender-specific of sexism language, and is frequently referred to be "he/man" language. For example, in the sentence: An instructor should offer his students challenging projects, "his" refers to the subject: an instructor. To examine instructor in a sense of gender, it is either a male or a female, yet his, a masculine pronoun used as the subject's reference covers the possibility of a female subject. Although the total number of woman exceeds 50 percent, the proportion of "he and she" existing in literature is $4: 1$. In other words, the masculine pronoun is the representative of either female or male reference. So it seems like a linguistic edition of the social inequality.

According to the rule of traditional grammar when the indefinite pronoun one is used for generic reference, then in the context usually one, one's, or himself is used to be its relevance. But in order to avoid repetition, he, his, him, or himself is chosen, especially in American English (Zhang Zhenbang,1995) See the examples,(1) If one wants to see the ruins, he must find his own guide. (2) Everyone must do his work well. In the first sentence, one refers to the concept of people, which is a concept of common gender, but the usage of masculine pronoun, he and his in the context formally manifests the imagery of men but semantically represents people of either gender. The operation of the grammatical rule conventionally elevates the status of the masculine pronouns and lowers the feminine ones.

\section{B. Generic Nouns}

Another well-known example of generic masculine term is "man". Man and woman as two equal components of human race are actually not equal in English lexicon. Man, besides its reference to male human being can also refer to the whole race. The usage in a general sense of man makes woman invisible. For example; (1) All men must die. (2) Man is a social animal. It is easy to see that "man", and "men" can be used generically to refer to both male and female. But "woman" and "women" cannot be employed in reference to men. When man appears in discourse, it is commendatory and positive in main circumstances. Look at the following idioms: (1) be man enough: brave enough (2) be one's own man: be able to arrange and decide things independently. However, situation involved woman is quite different: Look at the following examples:

(1) Wine, women, and song: drinking, dancing, etc, and enjoying oneself

(2) Make an honest woman of somebody: marry somebody having had sexual relationship with her.

In the English language, some words referring to female firstly are commendatory words, but afterward slowly have derogatory senses.

Survey in the dictionary on the illustrative idioms of man and woman as a quantity observation, derogation of woman is clearly seen. There are totally 33 illustrative idioms for man, of which 15 are with positive meaning, five negative and the rest are neutral with five shared by both man and woman in structure and meaning; While in case of woman, there are only 8 illustrative idioms of which five shared with man in structure and meaning, the rest are all derogatory. From this, one can know that in English using "man" or "men" indicates "the human race", they treat man as the center of the society, an embodiment of criterion and totally ignore the existence of woman.

\section{ORIGINS OF SEXISM IN ENGLISH}

With respect to the causes of sexism in English, it is regarded here that there are two major factors: one is social economic cause and the other is socialization. The following context will give a brief analysis on the main causes of sexism in English in terms of these two major aspects.

\section{A. Social Economic Causes}

It is the inequality status among men and women led sex discrimination. In this sense, sexism in the English language is rooted in the different attitudes towards men and women. The most important social cause, which initiates the different attitudes towards men and women, can be traced to labor division. Early in the human history, women were dominant in economic life. So women had a higher social status than men. During the process of human civilization, when human society entered patriarchal society, men took advantage of their physical strength and took the upper hand in economy and became more and more important in social economy. The social status of men gradually took over that of women. Women are restrained in limited area; they had to be dependent on men. They lost their social, economic and family status, and there came into being a long-stereotyped notion that women are responsible for domestic trifles, but men are working outside as breadwinners. The structure of the patriarchal society will be inevitable. Language is certainly indicated the superior status and central role of men but the inferior, passive role of women; hence, language is marked with discrimination towards women and sexism in language came forth.

\section{B. Socialization}

As we know, during the process of human civilization, which is also called as socialization, language formed and changed as time went by. Thus one of the most important causes of language sexism is the socialization. Socialization begins at birth. It shapes people to behave in appropriate ways. Much of people's behavior is the result of socialization. Children learn appropriate behavior through role models, games and toys, children's books and educational schools. They absorb the prejudice against girls and women in the sex-biased textbooks and develop according to gender 
stereotyping. For example, some children's books may suggest children that science is the field created for male. They educate male to be manly, decisive, and brave while girls are required to be polite, conservation, obedient, and gentle. Teachers, as well as parents, who are also important agents of socialization, tend to regard boys as more creative than girls, thereby creating much personality and behavioral patterns.

Mass media also have a great influence on people's view about gender.

People spent a lot of time watching TV and reading newspaper. So few people escape exposure to the vivid patterns of images, information and values in the world of mass media, among which some are sex-biased. Because of the effect of society and culture, the ideology of women's dependent on men has been deep-rooted and developed into a kind of social psychology.

To sum up, linguistic sexism is rooted in the social inequality between men and women. It may be social in origin rather than linguistic. So the success of eliminating sexism lies in the social change. If social inequality remains, linguistic attempts to achieve real equality are anything but impossible

\section{CONCLUSION}

The sexism in language is a very important new question for discussion, which has been attached importance by a lot of countries in the world. In nature , sexism in language is closely related to the phenomenon of gender discrimination in society, Since language is a social phenomenon and reflects social reality, origins of sexism in language are traced in the social background. In view of that language is not only a mirror which reflects social reality but also an instrument to perpetuates the social structure. Language planning should go in two directions. On the one hand, innovation of sexism language should carry out with aim to be consistent with the pace of the social changes and to unfold more and more role of women in social life; On the other hand, social reform with purpose to eliminate sex inequality should take lead. With high-speed development of society and scientific technology, our research on sexism in the English language will come to a new stage. The elimination of linguistic sexism lies in social change. Only by changing the social structure till one day when women and men own really equal status can language equality be truly achieved. Though the changes in social concept to make the changes in language naturally, finally realize that whether in society or language, sexism is just a history of past. The most important one is to erase the sexist conceptions and improve women's status, respect and support them. The language transformation can be realistic on the basis of the social reform.

\section{REFERENCES}

[1] Ronald Wardhaugh. (1986). An Introduction to Sociolinguistic. Basil Blackwell Inc.

[2] Song, Hongbo. (2002). Sexism in Language and Its Reform: A Comparative Study. A Thesis for the M.A. Degree in English Language and Literature.

[3] Fasold, Ralph (1990). The Socioliguistic of Language. Beijing: Foreign Language Teaching and Research Press. Blackwell Publisher Ltd.

[4] O’Gray, W, M. Bobrovolsky, M, Aronoff. (1997). A Contemporary Study. A Thesis for the M.A. Degree in English Language and Literature.

[5] Xu Lin. (2004). Sexism Analysis in English language. Xi'an University of Electronic Science and Technology,

[6] Wang-chun, SUN Ru-Jian, Yao Yuan. (1992). Social Psychology Linguistics. Shanghai: Shanghai Foreign Language Education Press,

[7] Chen Hua. (2005). Vocabulary Exploration of Gender Discrimination. Southwest China Normal University.

[8] Li Fu-yin, Yang Hua. (1997). See Gender Discrimination from the Part of Speech. Language Journal, 1997, No. 1.

Guimei He was born in Qingdao, China in 1957. She graduated from Liaocheng University in 1982, a bachelor degree. She is currently an associate professor in the College of Foreign Language of Qingdao Science and Technology University. 